\title{
Study of Effect of Spinning Process Variables on Fibre Length Parameters Using Taguchi Method
}

\author{
${\text { Akshay } \operatorname{Kumar}^{*}, 1, \text { S. M. Ishtiaque }}^{2}$ and K. R. Salhotra ${ }^{2}$ \\ ${ }^{I}$ The Abhishek Industries Ltd, Trident Complex, Barnala, Punjab, India \\ ${ }^{2}$ Department of Textile Technology, Indian Institute of Technology, New Delhi-110 016, India
}

\begin{abstract}
The effect of drafts at different stages of spinning process on fibre length distribution of slivers has been studied by using Taguchi Method and ANOVA technique. The L8 mixed orthogonal array was used to work out eight different slivers. Two different lap hanks, four different card drafts and two different draft/doublings at breaker and finisher were selected for the study. The fibrograph length measurements in terms of $2.5 \%, 50 \%$ and $66.7 \%$ span lengths and mean lengths (mean length and upper half mean length) were studied. The 50\% span length (SL) and $66.7 \%$ SL give an indication of fibre hooks in the sliver. These span lengths in card sliver first decrease and then increase with drafting at breaker and finisher sliver due to removal of hooks.
\end{abstract}

Keywords: Card draft, draft/doublings, lap hank, span lengths, mean lengths, hooks.

\section{INTRODUCTION}

The present trend in textile mills towards higher productions and higher drafts demands a strict observance of fibre configuration and fibre length parameters, at each stage of spinning process. The study of fibre configuration in yarn structure was initiated by Morton, Yen and Summers [1,2]. Thereafter, a number of researchers measured the fibre configuration in terms of various parameters like fibre extent, migration parameters, helix angle, type of hook, hook extent etc. These parameters can be grouped under a single heading called fibre orientation parameters. The properties of sliver, roving and yarns are mainly governed by these fibre orientation parameters [3].

Thus, in view of the recent developments in spinning it would be useful to study the effect of preparatory process variables (lap hank, card draft, draft/doublings) on fibre orientation parameters. The type of hooks, hook extent, and numbers of hooks were also measured in the yarn along with the fibre extent measurement. The study of fibre-overlap is a new approach to study the longitudinal behaviour of fibre in yarn. It was measured in terms of two newly proposed parameters $v i z$. fibre-overlap index (FOI) and fibre-pair-overlap length (FPO) [3].

The fibre length measurements can also be used both for assessing fibre breakage in processing and for fibre orientation at various process stages as done by some of the previous researchers [3-5]. In this regard, defining the fibre length distribution using fibrogram is an efficient way to study the fibre orientation and fibre breakage in spinning preparatory. Using fibrograph, length measurements can be defined either in term of mean lengths or span lengths.

*Address correspondence to this author at the The Abhishek Industries Ltd, Trident Complex, Barnala, Punjab, India; Tel: +919878998521, Pin 148101, E-mail: akshay_sardana@yahoo.com
In the present work, the effect of lap hank, card draft and draft/doublings at breaker \& finisher on fibre length measurements (mean lengths and span lengths) of slivers were studied using Taguchi Method [6].

\section{MATERIAL AND METHODS}

\subsection{Material}

Viscose rayon staple fibre ( $1.5 \mathrm{den}, 44 \mathrm{~mm})$ was processed on LR blow room line \& Texmaco Howa card and given two passages on LR DO/6 draw frame (breaker and finisher). The samples were prepared according to the L8 mixed orthogonal array as shown in the Table 1 . The design variable array shows that the two levels of lap hank, four levels of card draft and two sets of draft/doublings at breaker and finisher drawframe were selected. The factor levels at various stages were as chosen per some practical consideration. Firstly, the card is a very important process stage in spinning and hence a wide range of drafts was selected to study the effect of card draft. Secondly, there are only two type of draft/doublings commonly used in spinning process so two level of draft/doublings were selected.

\subsection{Test Methods}

The length measurements studied in slivers were based on both span lengths and mean lengths. The instrument used for analyzing length distribution was Kiosski's Classifiber Series model KCF/LS version 1.00.0. The span lengths measure of $2.5 \%, 50 \%$, and $66.7 \%$ and mean length measures of mean length (ML) \& upper half-mean length (UHM) were taken. The percentage short fibre content (SFC \%) at different stages was also measured.

\subsection{Analysis of Response}

There were two columns ( $\mathrm{i}=2)$ in the experimental result matrix for two different set of testing done for the various 
Table 1. Design Variable Array

\begin{tabular}{|c|c|c|c|c|c|}
\hline Run & Lap Hank (Ne) & Card Draft & Draft/Doublings at Drawframe (Breaker and Finisher) & \multicolumn{2}{|c|}{ Response } \\
\hline 1 & 0.00122 & 88 & $6 / 6$ & R11 & $\mathrm{R} 21$ \\
\hline 2 & 0.00144 & 88 & $8 / 8$ & $\mathrm{R} 12$ & $\mathrm{R} 22$ \\
\hline 3 & 0.00122 & 101 & $6 / 6$ & $\mathrm{R} 13$ & $\mathrm{R} 23$ \\
\hline 4 & 0.00144 & 101 & $8 / 8$ & R14 & $\mathrm{R} 24$ \\
\hline 5 & 0.00122 & 114 & $8 / 8$ & $\mathrm{R} 15$ & $\mathrm{R} 25$ \\
\hline 6 & 0.00144 & 114 & $6 / 6$ & R16 & $\mathrm{R} 26$ \\
\hline 7 & 0.00122 & 127 & $8 / 8$ & R17 & R27 \\
\hline 8 & 0.00144 & 127 & $6 / 6$ & $\mathrm{R} 18$ & $\mathrm{R} 28$ \\
\hline
\end{tabular}

fibre length measurement parameters (responses). Finally, $\mathrm{S} / \mathrm{N}$ ratio was calculated by using the formula given below for response "larger is better" for all fibre lengths measurement.

$$
S / N=-10 \cdot \log _{10} \cdot\left(1 / n \sum_{i=1}^{n} 1 / y_{i}^{2}\right)
$$

The actual values of $\mathrm{S} / \mathrm{N}$ ratio maximum were also evaluated directly from the curves of $\mathrm{S} / \mathrm{N}$ ratio with change in process variable by using the equation:

$$
\begin{aligned}
& \overline{S / N} \max =\overline{S / N}+(S / N A \max -\overline{S / N}) \\
& +(S / N B \max -\overline{S / N})+(S / N C \max -\overline{S / N})
\end{aligned}
$$

where,

$$
\begin{aligned}
& \overline{S / N \max }=\text { maximum actual value from the graph } \\
& \overline{S / N}=\text { overall average value of the } \mathrm{S} / \mathrm{N} \text { ratio } \\
& S / N A \max =\begin{array}{l}
\text { maximum value of } \mathrm{S} / \mathrm{N} \text { ratio in plot of lap } \\
\text { hank }
\end{array} \\
& S / N B \max =\begin{array}{l}
\text { maximum value of } \mathrm{S} / \mathrm{N} \text { ratio in plot of card } \\
\text { draft }
\end{array} \\
& S / N C \max =\begin{array}{l}
\text { maximum value of } \mathrm{S} / \mathrm{N} \text { ratio in plot of } \\
\text { draft } / \text { doublings }
\end{array}
\end{aligned}
$$

The calculated value is statistically compared with the actual value of $\mathrm{S} / \mathrm{N}$ ratio at $95 \%$ confidence level for significant difference between the two values. Like previous researchers [7] the rule followed was that if there is significant difference in the two values the experiment needs to be repeated by keeping the process variables at the optimum level observed from the graphs. Note that $\mathrm{S} / \mathrm{N}$ ratios of the various parameters should be maximized to get optimum set of process variables i.e for reading the plot, highest values of $\mathrm{S} / \mathrm{N}$ ratio are looked up for determining the optimum value of process variables in all the cases.

\section{RESULTS AND DISCUSSION}

The length measurements of parent fibre are shown in Table 2. Subsequently, Tables $\mathbf{3}$ to $\mathbf{5}$ show that the coefficient of correlation between mean values and $\mathrm{S} / \mathrm{N}$ ratios ap- proaches ' 1 '. So, $\mathrm{S} / \mathrm{N}$ ratio curves are used for interpretation of the effect of process variables on fibre length parameters due to effectiveness of $\mathrm{S} / \mathrm{N}$ ratio in taking the effect of uncontrollable variables into the account. The positive correlation between mean values and $\mathrm{S} / \mathrm{N}$ ratios in respective tables show that the response is of the type "larger is better" i.e. the increase in mean values also increases the $\mathrm{S} / \mathrm{N}$ ratios.

Table 2. Fibrograph Length Measurements of Parent Fibre

\begin{tabular}{|c|c|}
\hline $2.5 \%$ Span Length (SL), mm & 39.5 \\
\hline $50 \%$ SL, mm & 24.7 \\
\hline $66.7 \%$ SL, mm & 19 \\
\hline Mean Length (ML), mm & 41.5 \\
\hline Upper half mean (UHM), mm & 41.5 \\
\hline Short fibre content (SFC), \% & 0.1 \\
\hline
\end{tabular}

The overall percentage changes in responses by process variables and actual values of $\mathrm{S} / \mathrm{N}$ ratios at $95 \%$ confidence limits ( $/ \mathrm{N} \mathrm{L}$ and $\mathrm{S} / \mathrm{N} \mathrm{H}$ ) of the various parameters studied are also given in the respective tables. Since in all the cases the highest calculated values of $\mathrm{S} / \mathrm{N}$ ratio are lying within 95 $\%$ confidence limits for actual response by graphical method, no confirmatory test was done.

\subsection{Effect of Process Variables on Fibre Lengths Distri- bution in Slivers}

The test specimen is a random selection of fibres along their lengths to form a "beard". The beard simulates fibre orientation during sliver production processes, where fibres are randomly overlapping and parallel.

\subsubsection{Card Sliver}

Table 3 shows the values of $2.5 \%, 50 \%$ and $66.7 \%$ span length (SL) in card sliver in eight different experimental samples. Overall changes (\% C) in $\mathrm{S} / \mathrm{N}$ ratios and mean values of three span lengths tested are only marginal in which $66.7 \%$ span length shows maximum overall change and 2.5 $\%$ span length a negligible change. When, these span lengths in card sliver are compared with their corresponding parent values, it shows that the $2.5 \%$ SL slightly improves by process of carding. This is due to removal of fibre crimp in parent fibre by opening and drafting. But the $50 \%$ and $66.7 \%$ 
Table 3. S/N Ratios and Mean Values (in mm) of Fibre Length Measurements of Card Sliver

\begin{tabular}{|c|c|c|c|c|c|c|c|c|c|c|}
\hline Runs & \multicolumn{2}{|c|}{$2.5 \% \mathrm{SL}$} & \multicolumn{2}{|c|}{$50 \% \mathrm{SL}$} & \multicolumn{2}{|c|}{$66.7 \% \mathrm{SL}$} & \multicolumn{2}{|c|}{ ML } & \multicolumn{2}{|c|}{ UHM } \\
\hline 2 & 32.1 & 40.4 & 27.5 & 23.8 & 25.4 & 18.6 & 32.5 & 42.2 & 32.5 & 42.2 \\
\hline 3 & 32 & 39.7 & 27.2 & 22.8 & 24.9 & 17.5 & 32.3 & 41.1 & 32.4 & 41.5 \\
\hline 5 & 32 & 39.8 & 27.5 & 23.2 & 25 & 17.9 & 32.4 & 41.5 & 32.4 & 41.5 \\
\hline 6 & 31.9 & 39.3 & 27.1 & 22.7 & 24.8 & 17.4 & 32.2 & 40.8 & 32.3 & 41.2 \\
\hline 7 & 32.1 & 40 & 27.4 & 23.4 & 25.2 & 18.3 & 32.4 & 41.8 & 32.4 & 41.8 \\
\hline 8 & 32 & 39.8 & 27.3 & 23.1 & 24.9 & 17.5 & 32.4 & 41.7 & 32.4 & 41.7 \\
\hline S/N H & 32.3 & & 28.2 & & 26.1 & & 32.6 & & 32.7 & \\
\hline AVG & & 39.85 & & 23.26 & & 17.96 & & 41.56 & & 41.66 \\
\hline $\mathrm{r}$ & \multicolumn{2}{|c|}{0.933} & \multicolumn{2}{|c|}{0.891} & \multicolumn{2}{|c|}{0.988} & \multicolumn{2}{|c|}{0.962} & \multicolumn{2}{|c|}{0.918} \\
\hline
\end{tabular}

SL of card sliver are lower. This may be due to introduction of hooks in the process of carding [3-5].

Tables 6 and 7 show the changes in $2.5 \%, 50 \%$ and $66.7 \%$ span lengths in card sliver with change in lap hank and card draft. The majorities of changes in these span lengths are explained by change in card draft followed by lap hank. High values of $\mathrm{R}^{2}$ shows that the change in process variables alters the $2.5 \%, 50 \%$ and $66.7 \%$ SL in card sliver.
Figs. (1-3) show the $\mathrm{S} / \mathrm{N}$ ratio plot of $2.5 \%, 50 \%$ and $66.7 \%$ SL with change in lap hank and card draft. The trends of all the three span lengths are almost similar. Increase in lap hank and card draft decreases the span lengths in card sliver. This is due to increase in fibre hooks, inspite of possible better carding action, basically due to the lower carding force generated on the fibre due to less number of fibres in the operation layer of cylinder [3].

Table 4. S/N Ratios and Mean Values (in mm) of Fibre Length Measurements of Breaker Sliver

\begin{tabular}{|c|c|c|c|c|c|c|c|c|c|c|}
\hline Runs & \multicolumn{2}{|c|}{$2.5 \% \mathrm{SL}$} & \multicolumn{2}{|c|}{$50 \% \mathrm{SL}$} & \multicolumn{2}{|c|}{$66.7 \% \mathrm{SL}$} & \multicolumn{2}{|c|}{ ML } & \multicolumn{2}{|c|}{ UHM } \\
\hline 2 & 32.1 & 40.5 & 28 & 25 & 25.9 & 19.7 & 32.6 & 42.5 & 32.6 & 42.5 \\
\hline 3 & 32.2 & 40.7 & 28 & 25 & 25.9 & 19.7 & 32.6 & 42.5 & 32.6 & 42.5 \\
\hline 5 & 32.3 & 41 & 28.1 & 25.5 & 26.2 & 20.4 & 32.6 & 42.9 & 32.6 & 42.9 \\
\hline 6 & 32.2 & 40.3 & 27.4 & 23.4 & 25.1 & 18 & 32.5 & 42.2 & 32.5 & 42.2 \\
\hline 7 & 32 & 40 & 27.5 & 23.6 & 25.2 & 18.3 & 32.4 & 41.8 & 32.4 & 41.8 \\
\hline 8 & 32.3 & 41.1 & 28 & 25.1 & 25.9 & 19.8 & 32.7 & 43 & 32.7 & 43 \\
\hline $\mathrm{S} / \mathrm{N} \mathrm{H}$ & 32.6 & & 29.5 & & 28 & & 33.1 & & 33.1 & \\
\hline $\mathrm{AVG}$ & & 40.58 & & 24.45 & & 19.14 & & 42.46 & & 42.46 \\
\hline$r$ & \multicolumn{2}{|c|}{0.940} & \multicolumn{2}{|c|}{0.995} & \multicolumn{2}{|c|}{0.999} & \multicolumn{2}{|c|}{0.968} & \multicolumn{2}{|c|}{0.968} \\
\hline
\end{tabular}


Table 5. S/N Ratios and Mean Values (in mm) of Fibre Length Measurements of Finisher Sliver

\begin{tabular}{|c|c|c|c|c|c|c|c|c|c|c|}
\hline Runs & \multicolumn{2}{|c|}{$2.5 \% \mathrm{SL}$} & \multicolumn{2}{|c|}{$50 \% \mathrm{SL}$} & \multicolumn{2}{|c|}{$66.7 \%$ SL } & \multicolumn{2}{|c|}{ ML } & \multicolumn{2}{|c|}{ UHM } \\
\hline 2 & 32.2 & 41 & 28 & 25.1 & 25.9 & 19.8 & 32.6 & 42.8 & 32.6 & 42.8 \\
\hline 3 & 32.1 & 40.5 & 27.6 & 24.1 & 25.3 & 18.4 & 32.5 & 42.3 & 32.5 & 42.3 \\
\hline 5 & 32.1 & 40.5 & 27.7 & 24.1 & 25.4 & 18.6 & 32.5 & 42.3 & 32.5 & 42.3 \\
\hline 6 & 32.2 & 40.7 & 27.8 & 24.5 & 25.7 & 19.3 & 32.6 & 42.5 & 32.6 & 42.5 \\
\hline 7 & 32.2 & 41 & 28.1 & 25.5 & 26 & 20 & 32.6 & 42.8 & 32.6 & 42.8 \\
\hline 8 & 32.2 & 40.5 & 27.5 & 23.9 & 25.4 & 18.6 & 32.5 & 42.3 & 32.5 & 42.3 \\
\hline S/N H & 32.4 & & 29.2 & & 27.5 & & 32.8 & & 32.8 & \\
\hline AVG & & 40.74 & & 24.76 & & 19.34 & & 42.54 & & 42.54 \\
\hline $\mathrm{r}$ & \multicolumn{2}{|c|}{0.927} & \multicolumn{2}{|c|}{0.987} & \multicolumn{2}{|c|}{0.998} & \multicolumn{2}{|c|}{0.845} & \multicolumn{2}{|c|}{0.845} \\
\hline
\end{tabular}

\subsubsection{Breaker Sliver}

Table 4 shows the values of $2.5 \%, 50 \%$ and $66.7 \% \mathrm{SL}$ in breaker sliver in eight different experimental samples. Overall changes $(\% \mathrm{C})$ in $\mathrm{S} / \mathrm{N}$ ratio and mean values of $2.5 \%$ span length are only marginal. But the $50 \%$ and $66.7 \%$ span length show some overall change with the process of drafting at the breaker draw frame. When these span lengths in breaker sliver were compared with their corresponding values in card sliver. The 2.5\%, $50 \%$ and $66.7 \%$ SL are slightly improved by process of drafting. This may be mainly due to reduction in amount of hooks and enhanced orientation in sliver with the process of drafting [4,5].

Tables 6 and 7 show the changes in $2.5 \%, 50 \%$ and $66.7 \%$ span lengths in breaker sliver with change in process variables. The majorities of changes in these span lengths are explained by change in card draft followed by draft/ doublings and lap hank. Low values of $\mathrm{R}^{2}$ shows that the changes in process variables do not influence the $2.5 \%, 50 \%$ and $66.7 \%$ SL in breaker sliver much.

Figs. (1-3) show the $\mathrm{S} / \mathrm{N}$ ratio plot of $2.5 \%, 50 \%$ and $66.7 \%$ SL in breaker sliver with change in process variables. The trends of all the three span lengths are almost similar. Increase in lap hank increases the span lengths. This is mainly because better open material shows better straightening at draw frame giving rise to increase in span lengths. The increase in the card draft first increases (up to 101 card draft) and then decreases the span lengths in the breaker sliver. This is due to first decrease and then increase of proportion of hooks in sliver, as describe in some of related work of the authors [3]. The increase in draft/doublings increases the span lengths in the sliver. This is mainly due to process of

Table 6. Percentage Effect of Process Variables on Fibrograph Lengths Measurement in Terms of S/N Ratios

\begin{tabular}{|c|c|c|c|c|c|}
\hline Length Parameter & Parameter & \% Effect of Lap Hank & \% Effect of Card Draft & \% Effect of Draft/Doublings & $\% \mathrm{CP} *$ \\
\hline \multirow{2}{*}{$2.5 \% \mathrm{SL}$} & card sliver & 0.11 & 0.51 & & 0.8 \\
\hline & finisher sliver & 0.10 & 0.18 & 0.17 & 0.3 \\
\hline \multirow{2}{*}{$50 \% \mathrm{SL}$} & card sliver & 0.21 & 0.88 & & -5.8 \\
\hline & finisher sliver & 0.56 & 1.66 & 0.36 & 1.3 \\
\hline \multirow{3}{*}{$66.7 \% \mathrm{SL}$} & card sliver & 0.28 & 1.79 & & -5.5 \\
\hline & breaker sliver & 0.15 & 0.94 & 0.82 & 6.5 \\
\hline & finisher sliver & 0.29 & 2.48 & 0.36 & 1.0 \\
\hline
\end{tabular}

*Percentage change in mean value from previous machine, and in card change is depicted from parent fiber.

Note: Effect of variables are given in absolute term only. 
Table 7. Changes of S/N Ratios of Fibrograph Length Measurements as Assessed by ANOVA Technique and Taguchi Ranking

\begin{tabular}{|c|c|c|c|c|c|c|c|c|c|c|c|}
\hline \multirow[t]{2}{*}{$2.5 \% \mathrm{SL}$} & breaker sliver & 2 & 21.71 & 0.6 & 1 & 35.7 & 1.1 & 3 & 1.7 & 0.1 & 59 \\
\hline & finisher sliver & 3 & 12.73 & 0.5 & 1 & 21.5 & 0.8 & 2 & 35.0 & 2.3 & 69 \\
\hline \multirow[t]{2}{*}{$50 \% \mathrm{SL}$} & breaker sliver & 3 & 0.57 & 0.1 & 1 & 6.7 & 0.0 & 2 & 6.3 & 0.2 & 14 \\
\hline & finisher sliver & 2 & 9.19 & 0.9 & 1 & 48.8 & 0.5 & 3 & 3.8 & 0.2 & 62 \\
\hline \multirow[b]{2}{*}{$66.7 \% \mathrm{SL}$} & card sliver & 2 & 2.83 & 0.3 & 1 & 64.5 & 2.0 & & & & 67 \\
\hline & breaker sliver & 3 & 0.27 & 0.0 & 1 & 5.7 & 0.0 & 2 & 7.5 & 0.2 & 13 \\
\hline
\end{tabular}

*Variation in response due to change in value of the process variable.

enhanced straightening of hooks and improved orientation at relatively higher draft given at drawframe $[8,9]$.

\subsubsection{Finisher Sliver}

Table 5 shows that the values of $2.5 \%, 50 \%$ and $66.7 \%$ SL in finisher sliver are slightly higher than the respective values in breaker sliver. This shows that $2.5 \%, 50 \%$ and $66.7 \%$ SL slightly improve by drafting at finisher draw frame. This may be due to reduction in amount of hooks and decrease in fibre disorientation during drafting. Overall change $(\% \mathrm{C})$ in $\mathrm{S} / \mathrm{N}$ ratio and mean values of $2.5 \%$ span length are only marginal. The $50 \%$ and $66.7 \%$ span length show some overall change, though not considerable, due to drafting at the finisher draw frame.
Tables 6 and 7 show the change in $2.5 \%, 50 \%$ and 66.7 $\%$ span lengths in finisher sliver with change in process variables are marginal. The majorities of changes in these span lengths are attributed to change in card draft followed by draft/doublings and lap hank. $\mathrm{R}^{2}$ shows that the changes in process variables influence the $2.5 \%, 50 \%$ and $66.7 \%$ SL in finisher sliver.

Figs. (1-3) show the $\mathrm{S} / \mathrm{N}$ ratio plot of $2.5 \%, 50 \%$ and $66.7 \%$ SL in finisher sliver with change in process variables. The trends of all the three span lengths are almost similar. Increase in lap hank decreases the $50 \%$ and $66.7 \%$ span lengths (and marginally increase the $2.5 \%$ span length). The increase in the card draft first decreases and then slightly increases the span lengths in finisher sliver. The increase in

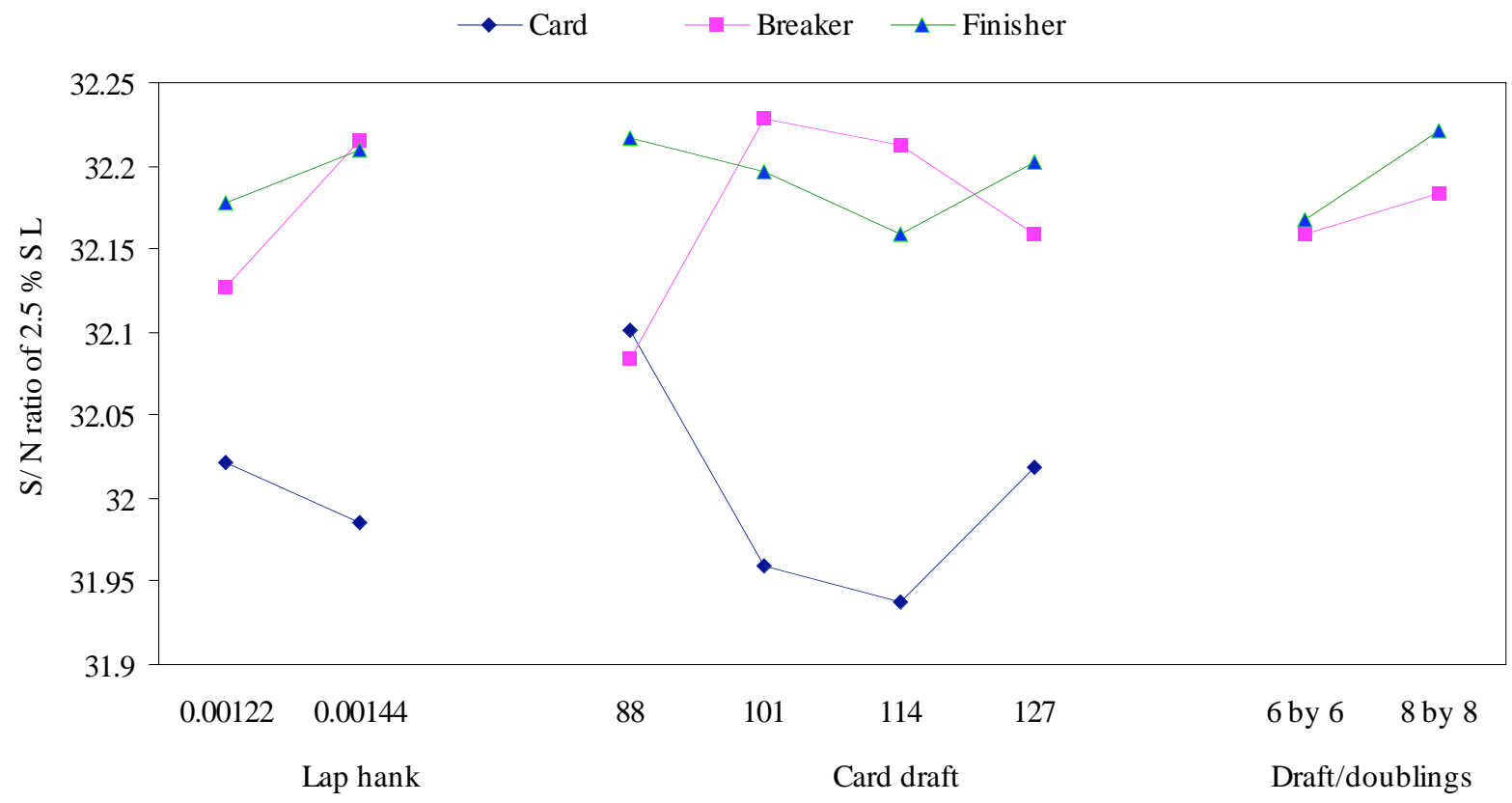

Fig. (1). S/N ratio plot of $2.5 \%$ span length in slivers with change in process variables. 


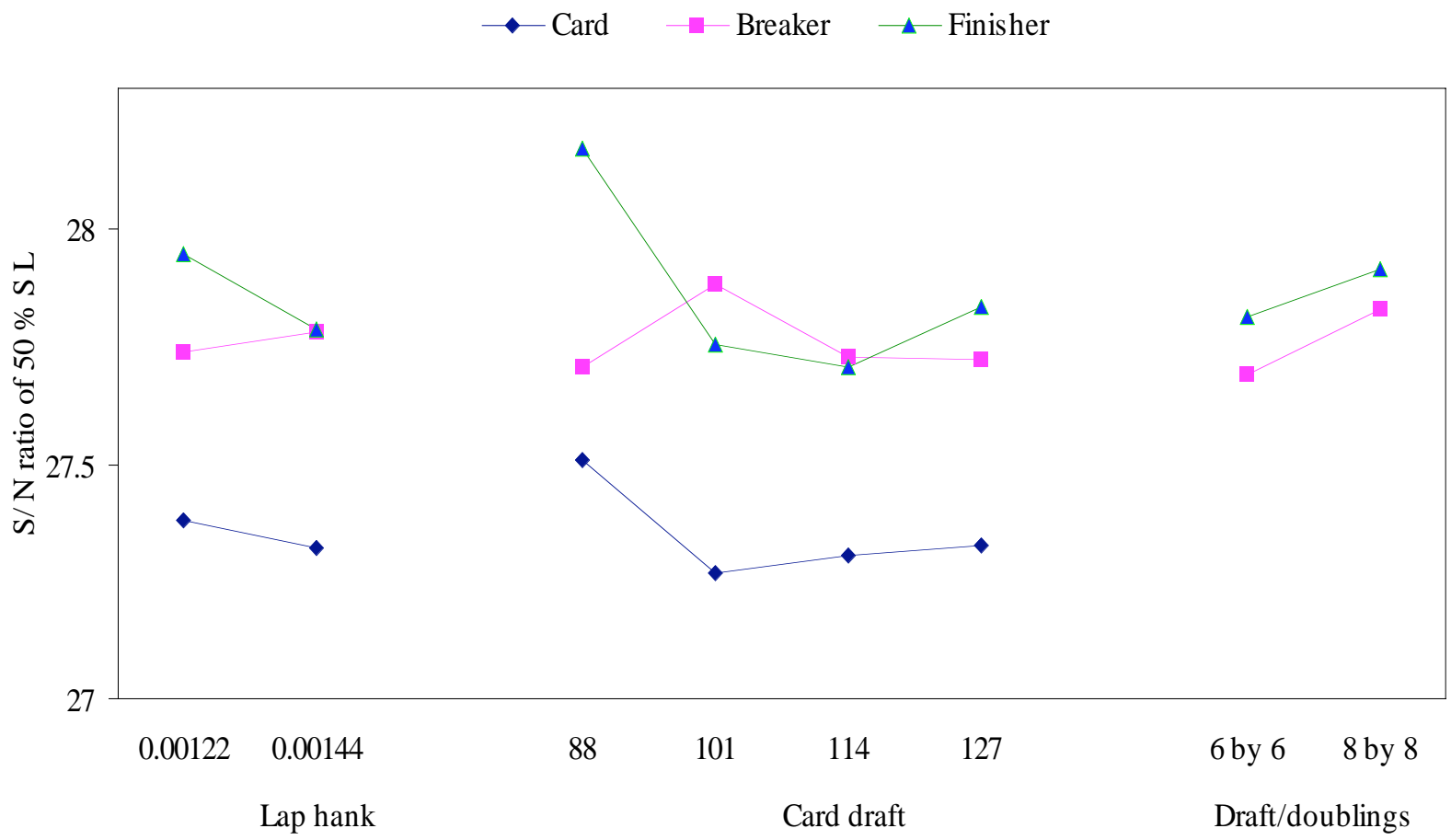

Fig. (2). S/N ratio plot of $50 \%$ span length in slivers with change in process variables.

draft/doublings also increases the span lengths in the sliver like in breaker sliver.

Further, Tables $\mathbf{3}$ to $\mathbf{5}$ show that mean and upper half mean lengths are almost the same in all the slivers due to well known square shape length distribution in manmade fibres. Figs. (4 and 5) show that the trends of upper half mean length and mean length are the similar. Further, the trends of mean lengths are found to be similar to those of span lengths, especially $2.5 \%$ span length, with change in process varaibles. So, the explanations given for change in span lengths in subsequent preparatory stages and with change in process variables are also applicable in the case of mean lengths.

Furthermore, the absolute values of SFC\% in all the cases are very small because there were hardly any fibre breakages in preparatory stages of card and blowroom.

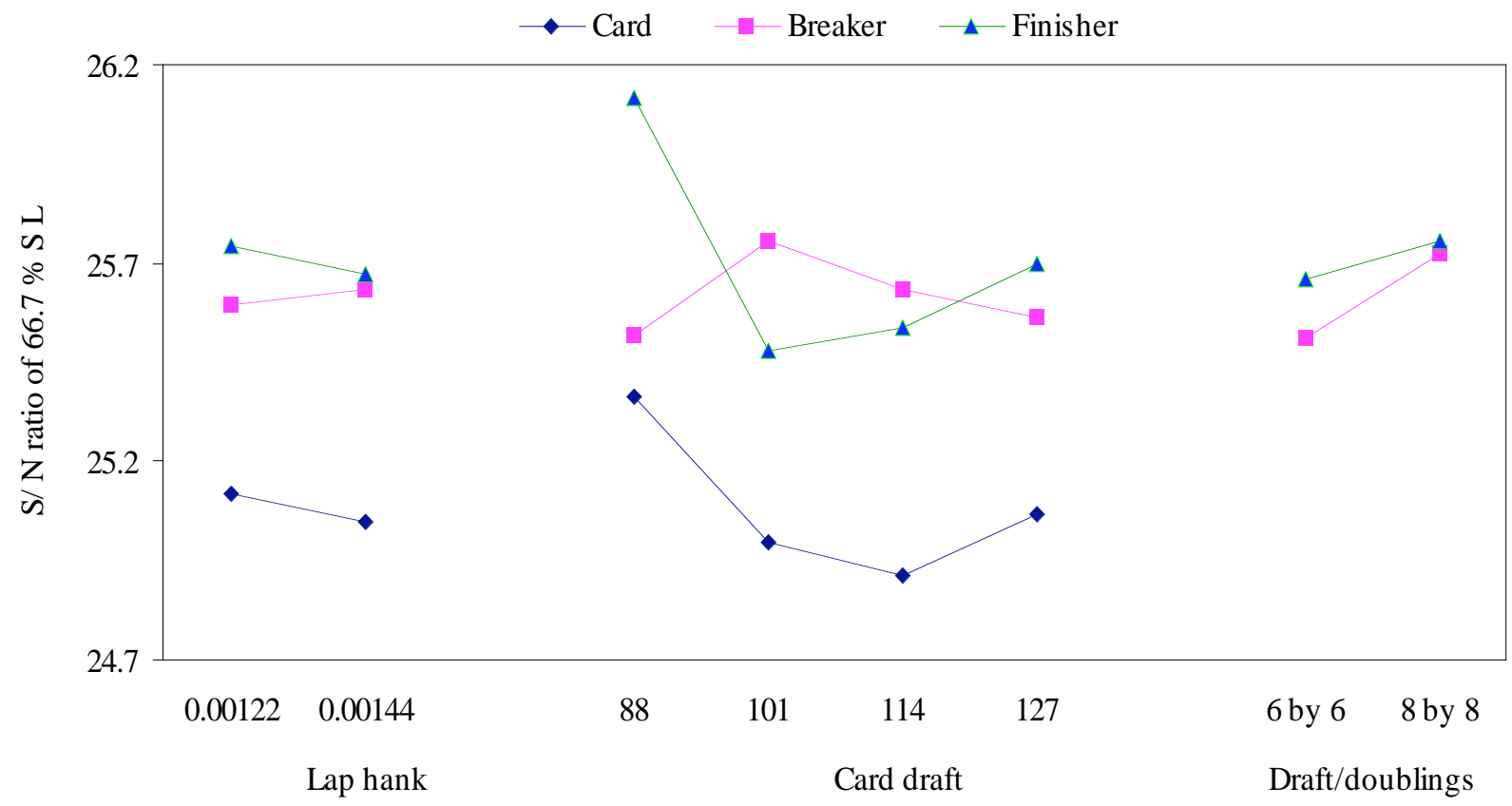

Fig. (3). S/N ratio plot of $66.7 \%$ span length in slivers with change in process variables. 


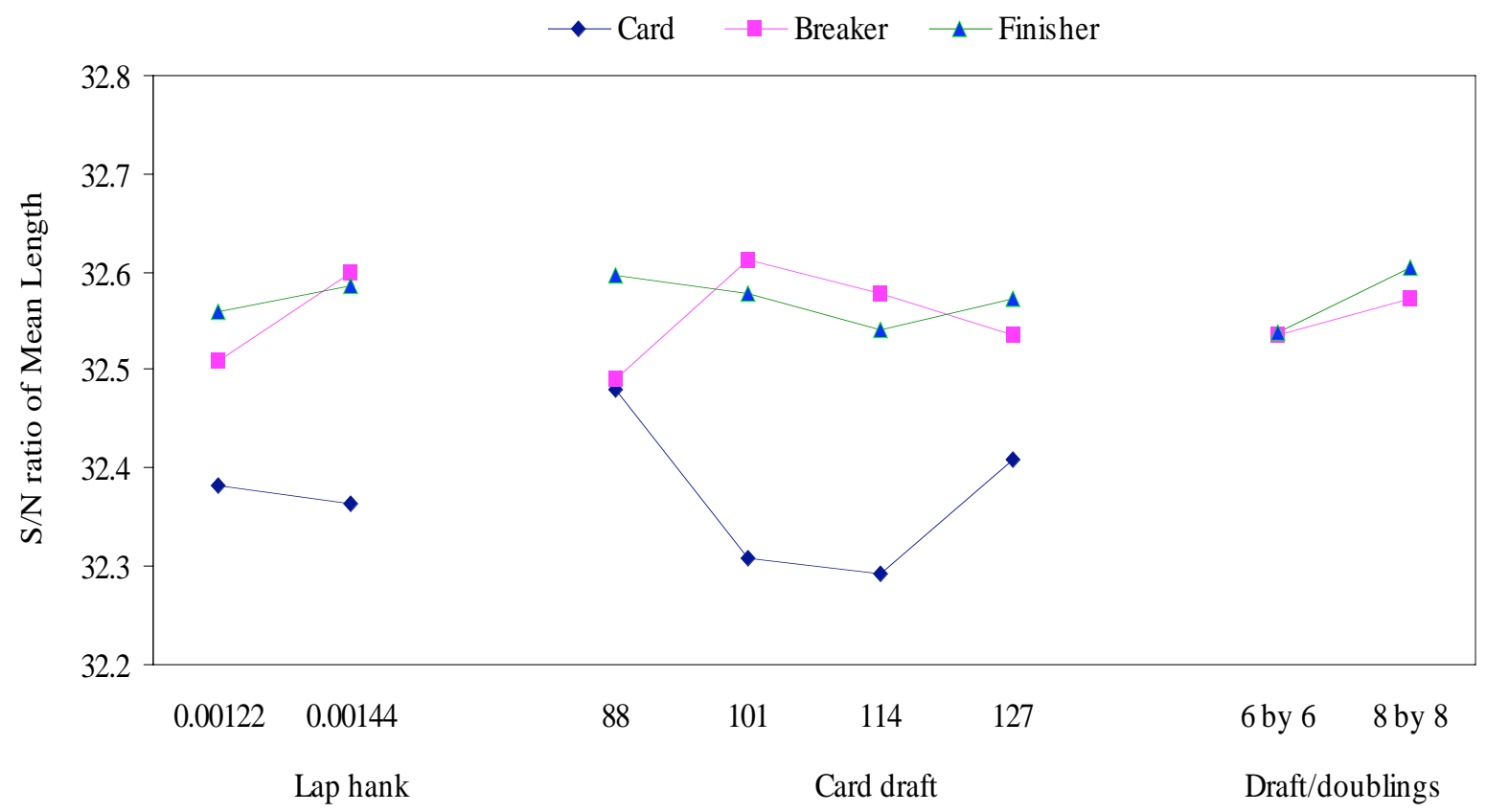

Fig. (4). $\mathrm{S} / \mathrm{N}$ ratio plot of mean length in slivers with change in process variables.

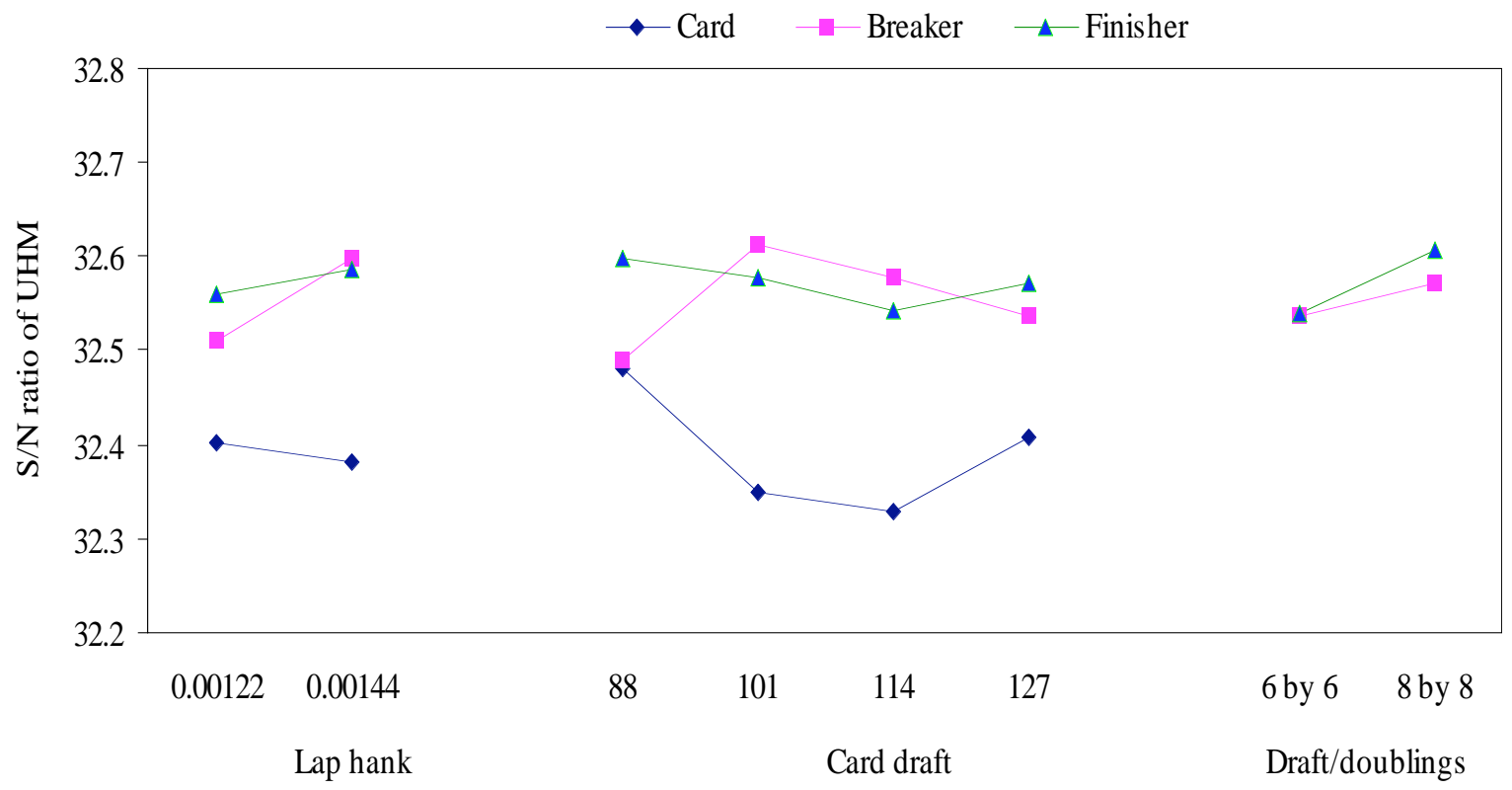

Fig. (5). S/N ratio plot of upper half mean length in slivers with change in process variables.

Table 6 and 7 shows that in all the slivers the effect of process variables on Fibre lengths measurement as shown in ANOVA table and ranked by Taguchi method are in agreement. This implies that the findings of Taguchi method are in agreement with widely used ANOVA technique. Thus, Taguchi method can be used to optimize the textile processes in a effective way.

\section{CONCLUSIONS}

Fibrogram of slivers in respect of spans lengths and mean lengths show that the length parameters marginally improve with drafting. The change of span lengths such as 50\% SL and $66.7 \%$ SL gives an indication of amount of hooks present in the slivers.

\section{REFERENCES}

[1] W. E. Morton, and K. C. Yen, "The arrangement of fibres in fibro yarns", J. Text. Inst., Vol. 43, pp. T463-T472, 1952.

[2] W. E. Morton, and R. J. Summers, "Fibre arrangement in card sliver", J. Text. Inst., Vol. 40, pp. 106- 110, 1949.

[3] K. R. Salhotra, S. M. Ishtiaque, and A. Kumar "Analysis of spinning process using Taguchi method part i: Effect of spinning proc- 
ess variables on fibre orientation in sliver and roving", J. Text. Inst. Vol. 97, No.4, pp. 271-283, 2006.

[4] R. Audivert, "The effect of fiber hooks on the digital fibrograph readings from clamped beards", Text. Res. J., Vol. 41, pp. 365-366, 1971.

[5] K. P. Iyer, M. S. Parathasarthy and V. Sundram, "Study on different methods of measuring fibre configuration", Resume of papers twenty first technological conference (ATIRA/BTRA/SITRA) Bombay Textile Research Association, Bombay, India, pp. 12-15, 1980.

[6] T. P. Bagchi, "Taguchi methods explained practical steps to robust Design”, Prentice hall of India Private Limited, New Delhi, 1993.
[7] J. Y. Ha, and C. K. Park, "Optimization of sewing conditions for seam pucker using Taguchi method", Conference CD proceedings of $7^{\text {th }}$ Asian Textile Conference (Textile Association India, New Delhi), 2003.

[8] R. Garde, V. A. Wakankar, and S. N. Bhaduri, "Fibre configuration in sliver and rovings and its effect on yarn quality", Text. Res. J., Vol. 31, pp. 1026-1036, 1961.

[9] S. K. Nerurkar, "Detailed analysis of carding quality and its influence on processing and yarn properties", Indian J. Text. Res., Vol. 4, pp. 63-70, 1979 .

Received: November 17, 2008

Revised: November 26, 2008

Accepted: February 08, 2009

(C) Kumar et al.; Licensee Bentham Open.

This is an open access article licensed under the terms of the Creative Commons Attribution Non-Commercial License (http://creativecommons.org/licenses/by$\mathrm{nc} / 3.0 /$ ), which permits unrestricted, non-commercial use, distribution and reproduction in any medium, provided the work is properly cited. 